\title{
Prenatale Moederlijke Stress en Cognitieve, Psychiatrische en Motorische Ontwikkelingsstoornissen van het Kind: Systematische
} Review

Rechtuijt, S.E. ${ }^{1}$, Noordermeer, S.D.S. ${ }^{1}$

${ }^{1}$ Vrije Universiteit, Sectie Klinische Neuropsychologie, Amsterdam

Correspondentieadres:

s.d.s.noordermeer@vu.nl

\section{Samenvatting}

Prenatale moederlijke stress (PNMS) heeft invloed op de ontwikkeling van het kind in diverse domeinen. Middels huidig literatuuronderzoek is onderzocht welke intensiteit van prenatale stress tot welke cognitieve, psychiatrische en motorische effecten op de ontwikkeling van het kind leidt. Daarbij is aanvullend onderzocht of milde dagelijkse PNMS ook invloed heeft, of dat er enkel bewijs is voor effecten van ernstige stress. Online databases zijn doorzocht op studies, hetgeen op basis van inclusiecriteria resulteerde in een totaal van veertien studies die meegenomen werden in het literatuuronderzoek. Er werd bewijs gevonden voor een negatief effect van milde PNMS op de cognitieve en psychomotorische ontwikkeling van het kind. Deze resultaten ondersteunen de door eerdere studies gevonden associaties met negatieve ontwikkelingsuitkomsten van het kind. Meer onderzoek naar de effecten van milde PNMS is echter nodig door het tot op heden kleine aantal uitgevoerde studies. Concluderend identificeert het huidig review naast ernstige en middelmatige stress ook milde stress als oorzaak van negatieve ontwikkelings-uitkomsten van het kind. 


\section{Inleiding}

De afgelopen decennia is er door verschillende studies gesuggereerd dat prenatale moederlijke stress (PNMS) invloed heeft op de ontwikkeling van het ongeboren kind [1-5]. PNMS kan leiden tot een lager geboortegewicht en een vroegere bevalling [6-9], emotionele- en gedragsproblemen als aandachtstekorthyperactiviteitsstoornis (attention deficit hyperactivity disorder; ADHD) [10, 11], normoverschrijdende gedragsstoornis (conduct disorder; CD) [11, 12], zelfgerapporteerde angst bij het kind [11, 13], taalproblemen [14] en een minder functionerend werkgeheugen $[15,16]$. Verder blijkt schizofrenie vaker voor te komen bij kinderen waarvan de moeder tijdens de zwangerschap ernstige stress ervaart $[17,18]$. Tot slot is er ook bewijs gevonden voor een veranderd functioneren van de hypothalamushypofyse-bijnier as (HPA-as) en veranderde niveaus van het stress gerelateerde hormoon cortisol in kinderen [11, 16, 19-21]. Verschillende studies richten zich op verschillende intensiteiten van stress. Zo zijn de effecten van ernstige stress door acute rampen zoals ' $9 / 11$ ' in New York [21], de atoomramp bij Chernobyl [10] en een Canadese ijsstorm [14] onderzocht. De resultaten wijzen op negatieve effecten van deze stressvolle gebeurtenissen op de ontwikkeling van het kind, waaronder een verhoogd risico op depressie en ADHD [10]. Prenatale blootstelling aan een middelmatig ernstige natuurramp bleek geassocieerd met lagere cognitieve vermogens en lagere taalvaardigheden van het kind op 5,5-jarige leeftijd [14]. Ook leidt een ernstige mate van stress als gevolg van de dood van een naast familielid mogelijk tot schizofrenie [17]. Daarnaast lijkt er een samenhang tussen ontwikkelingsuitkomsten van het kind en mildere stress, zoals alledaagse stress, of zwangerschaps-specifieke stress. Zo bleek een hoge mate van milde dagelijkse stress samen te hangen met lagere mentale en motorische ontwikkelingsscores bij baby's van 8 maanden [22]. Aan de andere kant is echter ook gerapporteerd dat een milde tot middelmatige mate van prenatale stress juist kan leiden tot een verbeterde mentale en motorische ontwikkeling 
[23]. Milde tot middelmatige stressniveaus zouden de foetale rijping in gezonde populaties kunnen verbeteren.

Dit wijst erop dat milde tot middelmatige stress in onze maatschappij ook kan leiden tot een optimale uitkomst van de ontwikkeling van het kind [23]. Tot op heden is het onduidelijk welke intensiteit en welk type stress tot welke uitkomsten in de ontwikkeling van het kind leidt. Inzicht in welk type stress tot welke ontwikkelingseffecten leidt, kan kennis completeren en zwangere vrouwen bewuster maken van de gevolgen van de stress die zij ervaren, en indien nodig hun werkdruk en stress verlagen. Huidig literatuuronderzoek geeft op basis van systematisch onderzoek een overzicht van welke mate en ernst van prenatale stress tot welke cognitieve, psychiatrische en motorische effecten op de ontwikkeling van het kind leiden. De gevolgen van stress op het kind worden onderverdeeld naar ontwikkelingsdomein: cognitieve uitkomsten, psychiatrische uitkomsten en motorische uitkomsten. Verwacht wordt dat alleen ernstige stress, en niet milde en middelmatige stress, leidt tot een afwijkende ontwikkeling van het kind op alle ontwikkelingsdomeinen. Het huidige onderzoek maakt een onderverdeling van stress in drie intensiteiten, namelijk milde stress, middelmatige stress en ernstige stress. Milde stress wordt gedefinieerd als nietchronische, kortdurende dagelijkse stress in reactie op milde stressoren.

Middelmatige stress wordt gedefinieerd als langer aanhoudende stress in reactie op milde stressoren. Ernstige stress wordt gedefinieerd als chronische stress in reactie op ernstige stressoren. Milde stressoren worden hier geoperationaliseerd als dagelijkse prikkels, zoals werkdruk of ruzie met een naaste. Middelmatige stressoren worden geoperationaliseerd als scheiding, gezondheidsproblemen, serieuze meningsverschillen met de partner of een andere naaste, financiële problemen, een grote baanverandering, serieuze problemen met betrekking tot huisvesting en serieuze problemen met de wetgeving. Ernstige stressoren worden geoperationaliseerd als oorlog, een natuurramp of dood of ziekte van een eerstegraads familielid. 


\section{Methoden, Studieselectie}

Voor huidig literatuuronderzoek zijn studies geïncludeerd die voldeden aan de volgende inclusiecriteria: (1) De studie is gericht op het effect van prenatale stress op cognitieve, psychiatrische of motorische uitkomsten van het kind, (2) de aanvang van de stressor vond plaats tijdens de zwangerschap, (3) de studie is gebaseerd op stress bij mensen en is geen dierstudie, (4) de kinderen waarop de uitkomsten van de studie van toepassing zijn hebben een minimale leeftijd van 6 maanden en een maximale leeftijd van 17 jaar, en (5) de studie beschrijft duidelijk aan wat voor stress de participanten blootgesteld waren, zodat deze in te delen is in één van de drie intensiteiten. De databases PubMed en PsycInfo werden doorzocht met de zoekterm 'prenatal stress effect'. Na de eerste oriënterende zoektocht werd op basis van het voldoen van de titel en abstract aan de inclusiecriteria een totaal van 24 studies geselecteerd. Deze studies werden geheel doorgenomen en verder gecontroleerd op geschiktheid op basis van de inclusiecriteria. Dit resulteerde in een totaal aantal van 14 studies (Zie Figuur 1).

\section{Resultaten}

Tabel 1 geeft een overzicht van de geïncludeerde studies. De totale steekproefgrootte varieerde voor alle geïncludeerde studies tussen de 54 en 1,38 miljoen individuen. Dit is bij elkaar een totaal aantal van 2.415.727 individuen. De kinderen in deze studie hadden een leeftijdsrange van 0 tot 21 jaar.

\subsection{Prenatale stress en de cognitieve uitkomsten van het kind}

Een totaal van drie studies rapporteerde over cognitieve uitkomsten als gevolg van prenatale stress. Kim et al. [24] rapporteerden dat jongens van 12 maanden van moeders die te maken hadden gehad met een hoge werkbelasting tijdens de zwangerschap, lagere cognitieve ontwikkelingsscores vertoonden dan jongens van moeders zonder hoge werkbelasting. Echter, meisjes van 12 maanden van moeders die te maken hadden met een hoge werkbelasting tijdens de zwangerschap, lagere cognitieve ontwikkelingsscores vertoonden dan jongens van moeders zonder hoge werkbelasting. Echter, meisjes van 12 maanden van moeders 
ISSN: 2589-8108 DOI: https://doi.org/10.31739/GGZV.2019.1.7 @ GGZ Vaktijdschrift, 2019;1(2):7-23

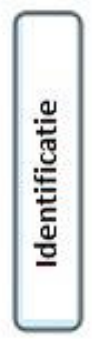

Records geïdentificeerd in
database
$(n=1170)$

Additionele records geïdentificeerd in andere bronnen $(n=5)$

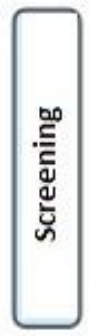

Records na verwijdering duplicaten

$$
(n=1169)
$$
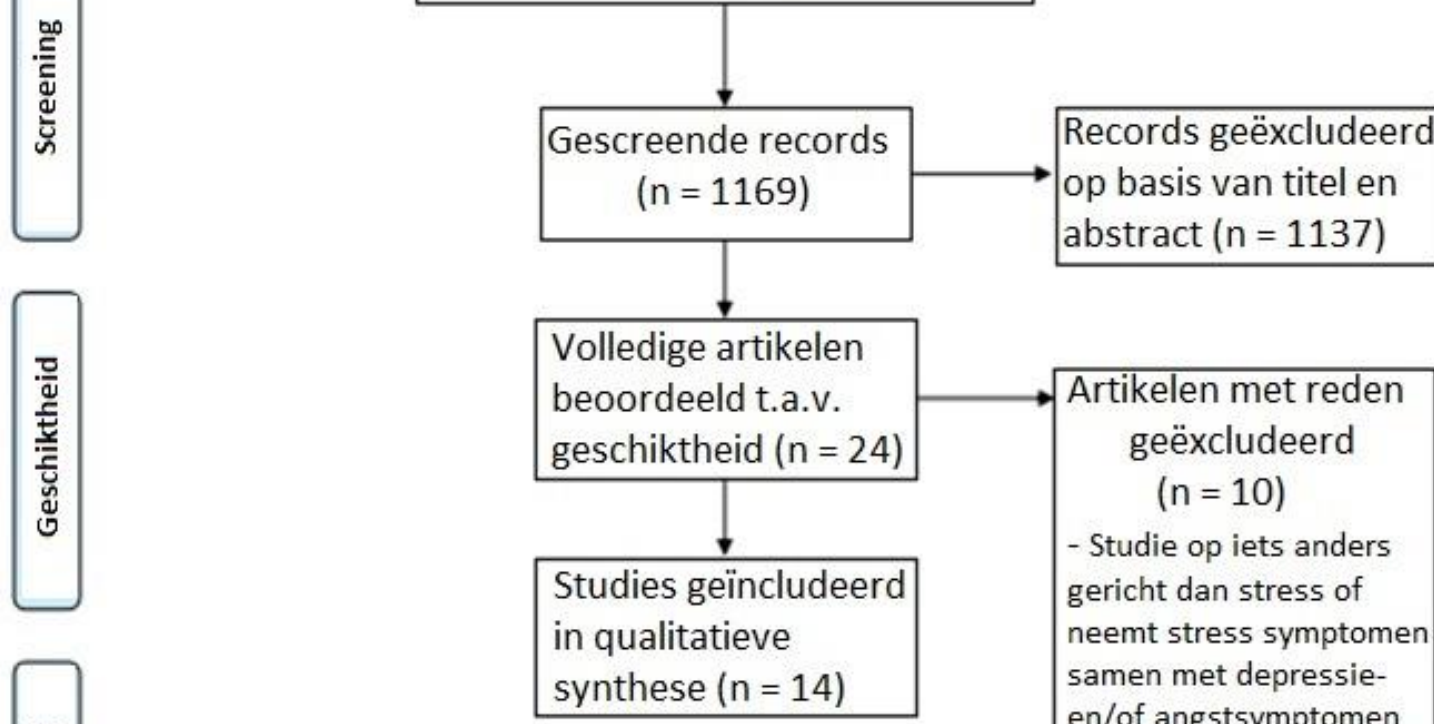
abstract $(n=1137)$

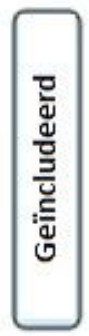

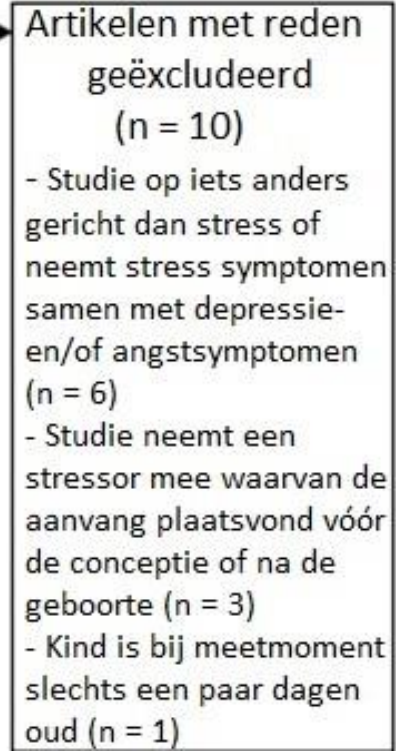

Figuur 1. PRISMA diagram van studie inclusie procedure 
ISSN: 2589-8108 DOI: https://doi.org/10.31739/GGZV.2019.1.7 O GGZ Vaktijdschrift, 2019;1(2):7-23

Rechtuijt en Noordermeer $\quad$ Prenatale Stress en Cognitieve, Psychiatrische en Motorische Ontwikkelingsstoornissen van het Kind: systematische review

Tabel 1. Overzicht van de geïncludeerde studies

\begin{tabular}{|c|c|c|c|c|c|c|}
\hline Studie & Onderwerp van de studie & $\begin{array}{l}\text { Sample } \\
\text { size }\end{array}$ & Leeftijd kinderen & Soort stress & $\begin{array}{l}\text { Soort } \\
\text { studie }\end{array}$ & Resultaten \\
\hline [25] & $\begin{array}{l}\text { A prospective study of effects of prenatal } \\
\text { maternal stress on later eating-disorder } \\
\text { manifestations in affected offspring: } \\
\text { preliminary indications based on the } \\
\text { Project Ice Storm cohort }\end{array}$ & 54 & 13 jaar & $\begin{array}{l}\text { Ernstige stress } \\
\text { (Quebec Ice } \\
\text { Storm) }\end{array}$ & $\begin{array}{l}\text { Birth- } \\
\text { cohort } \\
\text { study }\end{array}$ & $\begin{array}{l}\text { (Objectief ernstige) PNMS in het derde trimester is } \\
\text { geassocieerd met toegenomen eetstoornis-gerelateerde } \\
\text { manifestaties in vroege adolescenten }\end{array}$ \\
\hline [26] & $\begin{array}{l}\text { Prenatal and early life exposure to stressful } \\
\text { life events and risk of autism spectrum } \\
\text { disorders: population-based studies in } \\
\text { Sweden and England }\end{array}$ & 14.651 & 0-17 jaar & $\begin{array}{l}\text { Middelmatige } \\
\text { stress }\end{array}$ & $\begin{array}{l}\text { Longitudin } \\
\text { ale cohort } \\
\text { studie }\end{array}$ & $\begin{array}{l}\text { Geen bewijs gevonden voor de hypothese dat } \\
\text { blootstelling aan stressvolle levensgebeurtenissen tijdens } \\
\text { de prenatale periode geassocieerd is met een verhoogd } \\
\text { risico op autisme in de nakomelingen }\end{array}$ \\
\hline [24] & $\begin{array}{l}\text { Effect of maternal job strain during } \\
\text { pregnancy on infant neurodevelopment by } \\
\text { gender at } 6 \text { and } 12 \text { months: Mothers and } \\
\text { Children's Environmental Health } \\
\text { (MOCEH) study. }\end{array}$ & $\begin{array}{l}343 \\
\text { moeder } \\
\text {-kind } \\
\text { paren }\end{array}$ & $\begin{array}{l}\text { Metingen: in utero, } 6 \\
\text { maanden en } 12 \text { maanden }\end{array}$ & Milde stress & $\begin{array}{l}\text { Birth- } \\
\text { cohort } \\
\text { study }\end{array}$ & $\begin{array}{l}\text { Prenatale werkdruk beïnvloedt de neurodevelopment op } \\
\text { een sekse-afhankelijke manier }\end{array}$ \\
\hline [27] & $\begin{array}{l}\text { Sex-specific and time-dependent effects of } \\
\text { prenatal stress on the early behavioral } \\
\text { symptoms of ADHD: a longitudinal study } \\
\text { in China. }\end{array}$ & $\begin{array}{l}1765 \\
\text { moeder } \\
\text {-kind } \\
\text { paren }\end{array}$ & 48-54 maanden & $\begin{array}{l}\text { Geen stress, } \\
\text { middelmatige } \\
\text { stress en ernstige } \\
\text { stress }\end{array}$ & $\begin{array}{l}\text { Longitudin } \\
\text { al study }\end{array}$ & $\begin{array}{l}\text { Jongens wiens moeder aan ernstige PNMS had geleden in } \\
\text { het tweede trimester, hadden meer dan twee keer zoveel } \\
\text { kans op klinisch significante ADHD symptomen dan } \\
\text { jongens wiens moeder geen stress, middelmatige stress of } \\
\text { stress in het eerste of derde trimester had. Er werden geen } \\
\text { effecten gevonden voor meisjes. }\end{array}$ \\
\hline [28] & $\begin{array}{l}\text { Exposure to stressful life events during } \\
\text { pregnancy predicts psychotic experiences } \\
\text { via behaviour problems in childhood. }\end{array}$ & 2.227 & $\begin{array}{l}\text { Metingen: in utero, } 5 \text { jaar en } \\
21 \text { jaar }\end{array}$ & $\begin{array}{l}\text { Middelmatige } \\
\text { stress }\end{array}$ & $\begin{array}{l}\text { Pre-birth } \\
\text { cohort } \\
\text { study }\end{array}$ & $\begin{array}{l}\text { Middelmatige PNMS voorspelt latere psychotische } \\
\text { ervaringen via gedragsproblemen tijdens de kindertijd }\end{array}$ \\
\hline [29] & $\begin{array}{l}\text { Prenatal maternal stress predicts autism } \\
\text { traits in } 6 \frac{1}{2} \text { year-old children: Project Ice } \\
\text { Storm. }\end{array}$ & 89 & $\begin{array}{l}\text { Metingen: in utero en } 6,5 \\
\text { jaar }\end{array}$ & $\begin{array}{l}\text { Ernstige stress } \\
\text { (Quebec Ice } \\
\text { Storm) }\end{array}$ & $\begin{array}{l}\text { Birth- } \\
\text { cohort } \\
\text { study }\end{array}$ & $\begin{array}{l}\text { Prenatale blootstelling aan een milieuramp als de } 1998 \\
\text { Quebec Ice Storm verklaarde significante variantie in } \\
\text { autisme-achtige kenmerken van kinderen }\end{array}$ \\
\hline [30] & $\begin{array}{l}\text { Attention-deficit/hyperactivity disorder in } \\
\text { the offspring following prenatal maternal } \\
\text { bereavement: a nationwide follow-up study } \\
\text { in Denmark }\end{array}$ & 1.015 .9 & $\begin{array}{l}\text { Kinderen gevolgd vanaf } 3 \\
\text { jaar tot aan hun eerste } \\
\text { ADHD diagnose, eerste } \\
\text { gebruik van ADHD } \\
\text { medicatie of emigratie, of } \\
\text { einddatum van de studie }\end{array}$ & Ernstige stress & $\begin{array}{l}\text { Cross- } \\
\text { sectionele } \\
\text { studie }\end{array}$ & $\begin{array}{l}\text { Prenatale maternale blootstelling aan ernstige stress kan } \\
\text { het risico op ADHD in nakomelingen vergroten. }\end{array}$ \\
\hline [31] & $\begin{array}{l}\text { Prenatal maternal stress affects motor } \\
\text { function in } 5 \frac{1}{2} \text {-year-old children: project } \\
\text { ice storm. }\end{array}$ & 89 & 5,5 jaar & $\begin{array}{l}\text { Ernstige stress } \\
\text { (Quebec Ice } \\
\text { Storm) }\end{array}$ & $\begin{array}{l}\text { Birth- } \\
\text { cohort } \\
\text { study }\end{array}$ & $\begin{array}{l}\text { Hogere niveaus van objectieve ontbering en/of } \\
\text { subjectieve distress werden geassocieerd met lagere } \\
\text { motorische scores }\end{array}$ \\
\hline [10] & $\begin{array}{l}\text { Chernobyl exposure as stressor during } \\
\text { pregnancy and behaviour in adolescent } \\
\text { offspring }\end{array}$ & $\begin{array}{l}418 \\
\text { tweelin } \\
\text { gparen }\end{array}$ & 14 jaar & Ernstige stress & $\begin{array}{l}\text { Birth- } \\
\text { cohort } \\
\text { study }\end{array}$ & $\begin{array}{l}\text { Adolescenten die vanaf het tweede trimester blootgesteld } \\
\text { waren aan Chernobyl, hadden een twee keer zo groot } \\
\text { risico op depressie, major depressive disorder en ADHD }\end{array}$ \\
\hline [17] & $\begin{array}{l}\text { Higher risk of offspring schizophrenia } \\
\text { following antenatal maternal exposure to } \\
\text { severe adverse life events. }\end{array}$ & $\begin{array}{l}1,38 \\
\text { miljoen }\end{array}$ & $\begin{array}{l}\text { Follow-up vanaf } 10 \text { jaar tot } \\
\text { aan hun dood, migratie, } \\
\text { aanvang van schizofrenie of } \\
\text { de einddatum van de studie }\end{array}$ & Ernstige stress & $\begin{array}{l}\text { Population } \\
\text {-based } \\
\text { cohort } \\
\text { study }\end{array}$ & $\begin{array}{l}\text { Ernstige PNMS tijdens het eerste trimester van de } \\
\text { zwangerschap kan het risico op schizofrenie en } \\
\text { gerelateerde stoornissen in nakomelingen beïnvloeden }\end{array}$ \\
\hline [15] & $\begin{array}{l}\text { Maternal stress during pregnancy predicts } \\
\text { cognitive ability and fearfulness in infancy. }\end{array}$ & 123 & 14-19 maanden & $\begin{array}{l}\text { Middelmatige } \\
\text { stress }\end{array}$ & $\begin{array}{l}\text { Cohort } \\
\text { studie }\end{array}$ & $\begin{array}{l}\text { PNMS is negatief geassocieerd met mentale ontwikkeling } \\
\text { en positief geassocieerd met angst tijdens de kinderjaren }\end{array}$ \\
\hline [14] & $\begin{array}{l}\text { Stress during pregnancy affects general } \\
\text { intellectual and language functioning in } \\
\text { human toddlers. }\end{array}$ & 58 & 2 jaar & $\begin{array}{l}\text { Ernstige stress } \\
\text { (Quebec Ice } \\
\text { Storm) }\end{array}$ & $\begin{array}{l}\text { Longitudin } \\
\text { al study }\end{array}$ & $\begin{array}{l}\text { Hogere niveaus van prenatale blootstelling aan stress, met } \\
\text { name vroeg in de zwangerschap, kunnen de } \\
\text { hersenontwikkeling van de foetus negatief beïnvloeden, } \\
\text { hetgeen zich uit in een lagere intelligentie en een lager } \\
\text { taalvermogen in peuters }\end{array}$ \\
\hline
\end{tabular}


die te maken hadden met een hoge werkbelasting tijdens de zwangerschap vertoonden hogere cognitieve ontwikkelingsscores dan meisjes van moeders met een lage werkbelasting tijdens de zwangerschap. De studie van Kim et al. is de eerste studie die de relatie tussen stress gerelateerd aan werk en ontwikkelingsuitkomsten van het kind onderzocht.

Een eerdere studie [15] onderzocht het effect van PNMS op de mentale ontwikkeling van het kind. De mentale ontwikkeling bestond binnen deze studie uit sensorische en perceptuele scherpte, discriminatie tussen en respons op objecten, verwerving van objectpermanentie, geheugen, probleemoplossend vermogen, stemgebruik, het begin van verbale communicatie, de basis van abstract denken, het mentaal in kaart brengen van objecten, habituatie, complexe taal en mathematische conceptformatie. Bergman et al. vonden dat PNMS de mentale ontwikkeling voorspelde. Dit effect werd ook gevonden na controle voor postnatale stressoren, opleiding van de moeder en psychologische staat, blootstelling aan medicatie en substanties tijdens de zwangerschap, en geboorte-uitkomsten. Prenatale stress verklaarde $17 \%$ van de variantie in cognitief vermogen. De stress in deze studie werd gecategoriseerd als middelmatige stress en was geassocieerd met een mindere mentale ontwikkeling. Laplante et al. [32] onderzochten het effect van PNMS op intellectuele ontwikkeling en taalontwikkeling. Als stressor werd de Quebec ijsstorm gebruikt. Deze grote ijsstorm raasde in 1998 over Canada met 35 doden tot gevolg en een enorme schade aan de natuur en een wekenlange uitval van elektriciteit. De blootstelling aan prenatale stress verklaarde $17.3 \%$ van de variantie van de receptieve taalvaardigheid van de peuters. Hoe ernstiger de blootstelling aan prenatale stress, ofwel hoe meer impact deze stress op de moeder had, des te slechter de taalvaardigheden van de peuter. De onderzoekers concludeerden dat een hoger niveau van prenatale blootstelling aan stress, met name vroeg in de zwangerschap, de ontwikkeling van de foetus negatief kan beïnvloeden. Dit 
wordt gereflecteerd in een slechter algemeen intelligentievermogen en slechtere taalvaardigheden in peuters ten opzichte van peuters die tijdens de zwangerschap niet blootgesteld waren aan stress.

Al met al blijkt in het cognitieve domein een effect van prenatale stress op de cognitieve ontwikkeling, mentale ontwikkeling, intellectuele ontwikkeling en taalontwikkeling. Milde PNMS hangt samen met cognitieve ontwikkelingsscores (negatief voor jongens en positief voor meisjes). Middelmatige PNMS bleek negatief samen te hangen met de mentale ontwikkeling van het kind. Ook werd er een negatief verband gevonden tussen ernst van de PNMS en het intelligentievermogen en de taalvaardigheden van peuters.

\subsection{Prenatale stress en de}

\section{psychiatrische uitkomsten van het}

\section{kind}

Een totaal van 10 studies rapporteerde over psychiatrische uitkomsten als gevolg van prenatale stress. $\underline{\text { Psychotische ervaringen/schizofrenie }}$

Een redelijk recente studie [28]

onderzocht het effect van PNMS op

psychotische ervaringen bij

jongvolwassenen. Het betreft een longitudinale studie waarbij door de jaren heen meerdere metingen plaatsvonden, onder andere van gedragsproblemen op vijfjarige leeftijd. De onderzoekers rapporteerden dat PNMS psychotische ervaringen voorspelde en dat dit indirect gebeurde via gedragsproblemen op vijfjarige leeftijd. De neurologische ontwikkelingsgevolgen van PNMS uiten zich eerst als gedragsproblemen in de kindertijd en resulteren later in een groter risico op psychotische ervaringen. $\mathrm{Na}$ controle voor stress van de moeder wanneer het kind 5 jaar was, bestond de relatie nog steeds. Er werd hierbij geen interactie gevonden tussen prenatale stressvolle levensgebeurtenissen en gedragsproblemen of cognitief vermogen. De PNMS in die studie werd gecategoriseerd als middelmatige stress. Het blijkt dus dat middelmatige PNMS latere psychotische ervaringen via gedragsproblemen tijdens de kindertijd kan voorspellen. 
In een andere studie [17] werd het effect van PNMS op het risico op schizofrenie en gerelateerde stoornissen bij kinderen nagegaan. Ernstige PNMS tijdens het eerste trimester van de zwangerschap vergrootte het risico op schizofrenie en gerelateerde stoornissen bij de nakomelingen. De stressor die in deze studie gehanteerd werd, was de dood van een familielid tijdens het eerste trimester. Er werden geen verbanden gevonden tussen stress door de dood van een familielid tijdens andere trimesters of tot zes maanden voor de zwangerschap en een hoger risico op schizofrenie.

\section{$\underline{\text { Autisme }}$}

Walder et al. [29] onderzochten het effect van PNMS op kenmerken binnen het autisme spectrum. Middels de studie werd aangetoond dat zowel objectieve stress als subjectieve onrust bij de moeder geassocieerd waren met meer dan zeven kenmerken binnen het autisme spectrum, hoewel de meeste kinderen in de subklinische range scoorden. De studie concludeert dat prenatale blootstelling aan een milieuramp als de 1998 'Quebec Ice Storm’ significante variantie in de kenmerken binnen het autisme spectrum van kinderen

verklaarde, zelfs in een zeer

sociaaleconomisch bevoordeelde

steekproef. De studie suggereert dat chronische stressoren de neurologische ontwikkeling kunnen beïnvloeden en het risico op autisme vergroten, maar dat acute stressoren dit niet doen. De studie hanteerde zelf sterfgevallen, ernstige ongevallen, letsel of gebeurtenissen en een diagnose van een familielid met een levensbedreigende of ernstige ziekte, als stressoren.

\section{Eetstoornissen}

Een prospectieve studie van St-Hilaire et al. [25] onderzocht de impact van de ervaringen van een omgevingsstressor van moeders terwijl zij zwanger waren op de latere ontwikkeling van onaangepast eetgedrag van hun kind. De resultaten geven aan dat blootstelling van de moeder aan objectief ernstige stress ('Quebec Ice Storm') in de latere fase (derde trimester) van de zwangerschap geassocieerd was met een hoger risico op eetstoornissen bij de deze nakomelingen. Deze associatie was er ook na controle voor geslacht (vrouw zijn) en BMI. Blootstelling aan stress 
tijdens een latere fase van de zwangerschap was sterker geassocieerd met het risico op eetstoornissen.

Gesuggereerd werd dat met name de latere periode in de zwangerschap een kwetsbare periode is voor het kind. Hoe ernstiger de objectieve omgevingsstress van de moeder tijdens de ijsstorm was, des te waarschijnlijker het was dat haar kind uiteindelijk verstoord eetgedrag zou vertonen.

\section{$\underline{\mathrm{ADHD}}$}

Li et al. [30] onderzochten het effect van PNMS als gevolg van een overleden kind of echtgenoot op het risico op ADHD. Gevonden werd dat jongens van wie de moeder een kind of echtgenoot verloren had tijdens de zwangerschap een hoger risico hadden op een diagnose van ADHD of op het krijgen van ADHD medicatie. Deze associaties werden niet gevonden voor meisjes en niet voor rouw door de dood van familieleden anders dan een kind of echtgenoot. De studie concludeert daarom dat ernstige PNMS een rol kan spelen in de ontwikkeling van ADHD bij mannelijke nakomelingen.

Een recente studie van Zhu et al. [27] onderzocht het effect van ernstige stressvolle levensgebeurtenissen bij moeders op gedragssymptomen horend bij ADHD. Aangetoond werd dat jongens van wie de moeder een dergelijke gebeurtenis had ervaren tijdens het tweede trimester, maar niet het eerste of derde trimester, meer dan twee keer zoveel kans hadden om klinisch significante gedragssymptomen van ADHD te hebben. Dit was na controle voor omvangrijke verstorende factoren. Echter, voor meisjes van wie de moeder prenataal een ernstige levensgebeurtenis had ervaren, werd er geen significant toegenomen risico op ADHD symptomen geobserveerd. De studie suggereert dus dat de vroege ontwikkeling van gedrag van mannelijke nakomelingen kwetsbaarder is voor PNMS dan dat van vrouwelijke nakomelingen. Daarnaast suggereert het dat het middelste deel of de tweede helft van de zwangerschap een kritisch raam is waarin PNMS een grotere invloed heeft op de ontwikkeling van ADHD symptomen.

Huizink et al. [10] onderzochten het effect van prenatale blootstelling aan de ramp van Chernobyl, gecategoriseerd als 
ernstige stress, op ADHD symptomen. Gerapporteerd werd dat adolescenten van wie de moeder vanaf het tweede trimester van de zwangerschap blootgesteld was aan de ramp van Chernobyl, een twee keer zo groot risico hadden op het ontwikkelen van ADHD symptomen. Dit effect werd alleen gevonden onder de adolescenten die vanaf het tweede trimester blootgesteld waren, en niet vanaf het derde trimester of slechts tijdens het derde trimester. De resultaten waren gecontroleerd voor maternale depressieve symptomen, $\mathrm{CD}$, antisociale persoonlijkheidsstoornis, symptomen van alcoholgebruik of misbruik en maternaal roken tijdens de zwangerschap.

\section{Depressie}

Omdat depressie in recente onderzoeken wordt gelinkt aan afwijkingen in functionele connectiviteit in het sensorische systeem [33] lijkt een verband met prenatale stress plausibel. Huizink et al. [10] onderzochten ook het effect van prenatale blootstelling aan de ramp van Chernobyl, gecategoriseerd als ernstige stress, op depressiesymptomen. Gerapporteerd werd dat adolescenten van wie de moeder vanaf het tweede trimester van de zwangerschap blootgesteld was aan de ramp van Chernobyl, een twee keer zo groot risico hadden op de ontwikkeling van levenslange depressiesymptomen. Dit effect werd enkel gevonden onder de adolescenten van moeders die vanaf het tweede trimester blootgesteld waren, en niet vanaf het derde trimester of enkel tijdens het derde trimester. De resultaten waren gecontroleerd voor maternale depressieve symptomen, $\mathrm{CD}$, antisociale persoonlijkheidsstoornis, symptomen van alcoholgebruik of -misbruik en maternaal roken tijdens de zwangerschap.

Samenvattend werden er in het psychiatrische domein resultaten gevonden voor psychotische ervaringen/schizofrenie, autisme, eetstoornissen, ADHD en depressie. Middelmatige PNMS bleek positief samen te hangen met psychotische ervaringen, welke indirect voorspeld werden middels gedragsproblemen op vijfjarige leeftijd. Ernstige PNMS gedurende het tweede trimester bleek samen te hangen met een hoger risico op schizofrenie. Ernstige PNMS bleek ook 
samen te hangen met een grotere kans op autisme, maar dit gold alleen voor een ernstige chronische stressor als een natuurramp en niet voor ernstige acute stressoren als sterfgevallen, ongevallen en ziekte. Ook bleek ernstige PNMS door een natuurramp geassocieerd met een hoger risico op eetstoornissen. Meerdere studies vonden een positieve associatie tussen ernstige PNMS en ADHD. In twee van de drie studies werd dit effect alleen gevonden voor stress gedurende het tweede trimester. Twee van de drie studies vonden alleen een effect voor jongens en niet voor meisjes. Tot slot werd er een positieve associatie gevonden tussen ernstige PNMS en depressiesymptomen.

\subsection{Prenatale stress en de motorische uitkomsten van het kind.}

Een totaal van twee studies rapporteerde over motorische uitkomsten als gevolg van prenatale stress. De meest recente studie (Kim et al.) [24] onderzocht het effect van hoge werkbelasting tijdens de zwangerschap op de psychomotoriek van het kind. Gerapporteerd werd dat jongens van 12 maanden van moeders die te maken hadden met een hoge werkbelasting tijdens de zwangerschap, lagere psychomotorische ontwikkelingsscores vertoonden dan jongens van moeders zonder hoge werkbelasting. Voor meisjes van moeders met een hoge werkbelasting werd geen verschil gevonden met meisjes van moeders zonder hoge werkbelasting.

Een andere studie van Cao et al. [31] ging het effect na van stress als gevolg van de Quebec Ice Storm op motoriek, balans en visueel motorische integratie van het kind. Gevonden werd dat hogere niveaus van objectieve ontbering en/of subjectieve onrust met betrekking tot de Quebec Ice Storm, hetgeen gecategoriseerd kan worden als ernstige stress, geassocieerd waren met lagere motorische scores op balans en visueel motorische integratie. Er werd geconcludeerd dat een hoog niveau van subjectieve onrust een universeel schadelijk effect had op de motorische functies van kinderen.

Samenvattend is er in het motorische domein bewijs gevonden voor een effect van PNMS op de psychomotorische ontwikkeling en motoriek (balans en visueel motorische integratie). Er is hier 
een negatieve associatie tussen milde PNMS en psychomotoriek bij jongens, maar niet bij meisjes. Ook werd een negatieve associatie gevonden tussen ernstige PNMS en motoriek, waarbij geen onderscheid werd gemaakt tussen jongens en meisjes.

\section{Discussie}

Het doel van de huidige literatuurstudie was om op basis van systematisch onderzoek een duidelijk overzicht te geven van welke mate en ernst van prenatale stress leidt tot welke cognitieve, psychiatrische en motorische effecten op de ontwikkeling van het kind. Daarbij werd ten doel gesteld om aanvullend te beantwoorden of milde dagelijkse stress bij zwangere vrouwen ook invloed heeft, of dat er enkel bewijs is voor de effecten van ernstige stress door bijvoorbeeld rampen en overleden naasten.

De huidige studie vond dat milde prenatale stress negatief geassocieerd is met de cognitieve en psychomotorische ontwikkeling van een kind.

Middelmatige stress was negatief geassocieerd met de mentale ontwikkeling en positief geassocieerd met psychotische ervaringen in de latere adolescentie van een kind. Ernstige stress was negatief geassocieerd met motoriek (balans en visueel motorische integratie) en positief geassocieerd met schizofrenie, autisme, eetstoornissen, ADHD en depressiesymptomen. Samenvattend lijkt het dat de meeste uitkomsten van het kind als gevolg van PNMS samenhangen met ernstige prenatale stress. Toch zijn er twee associaties gevonden met milde stress. Geconcludeerd wordt daarom dat ook milde dagelijkse stress een negatieve invloed kan hebben op de ontwikkelingsuitkomsten bij het kind. De resultaten zijn niet in lijn met de vooraf opgestelde verwachting dat alleen ernstige stress, en niet milde en middelmatige stress, kan leiden tot een afwijkende ontwikkeling van het kind op alle ontwikkelingsdomeinen. Dit kan mogelijk verklaard worden doordat elke stressreactie, ongeacht de intensiteit, een fysieke stressrespons genereert welke impact kan hebben op het ongeboren kind. De resultaten ondersteunen de door eerdere studies gevonden associaties met negatieve ontwikkelingsuitkomsten van het kind wel [1-5, 10-18]. 
Een beperking van de huidige literatuurstudie is dat er per domein slechts een klein aantal studies is gevonden. Daarnaast werden alle studies, waarbij het gecombineerde effect van PNMS en angst werd onderzocht, uitgesloten. Er bleek echter een relatief groot aantal studies te zijn waarbij dit gecombineerde effect werd onderzocht. Een suggestie voor vervolgonderzoek is daarom om ook studies die het gecombineerde effect van stress en angst onderzoeken mee te nemen.

Verder zouden toekomstige studies zich ten behoeve van de objectiviteit kunnen richten op daadwerkelijke (Diagnostic and Statistical Manual of Mental Disorders) diagnoses van ontwikkelingsstoornissen in plaats van op 'stoornisachtige kenmerken'. Meer algemeen wordt voor toekomstige studies nog gesuggereerd om eenzelfde instrument te gebruiken om de ernst van PNMS te meten. Ook dit komt de objectiviteit en generaliseerbaarheid van studies ten goede en maakt het mogelijk resultaten beter te vergelijken.

Al met al kan geconcludeerd worden dat zelfs milde dagelijkse prenatale stress negatieve gevolgen kan hebben voor de cognitieve en psychomotorische ontwikkeling van het kind. Daarom is het van belang dat hier meer rekening mee wordt gehouden, bijvoorbeeld middels voorlichting van zwangere vrouwen en het verlagen van hun werkdruk, ter preventie van negatieve ontwikkelingsuitkomsten van het kind. Meer onderzoek naar de effecten van milde prenatale stress en het gebruik van eenzelfde meetinstrument voor de meting van de ernst van stress kunnen worden aangemoedigd. Hoe dan ook kunnen wij met voorzichtigheid concluderen dat het huidig review aanwijzingen geeft dat milde stress een oorzaak kan zijn van negatieve ontwikkelingsuitkomsten van het kind.

\section{Referenties}

1. Beydoun, H. and A.F. Saftlas, Physical and mental health outcomes of prenatal maternal stress in human and animal studies: a review of recent evidence. Paediatric and perinatal epidemiology, 2008. 22(5): p. 438-466.

2. Mulder, E.J., et al., Prenatal maternal stress: effects on pregnancy and the (unborn) child. Early human development, 2002. 70(1-2): p. 3-14.

3. Talge, N.M., et al., Antenatal 
ISSN: 2589-8108 DOI: https://doi.org/10.31739/GGZV.2019.1.7 @ GGZ Vaktijdschrift, 2019;1(2):7-23

Rechtuijt en Noordermeer $\quad$ Prenatale Stress en Cognitieve, Psychiatrische en Motorische Ontwikkelingsstoornissen van het Kind: systematische review

maternal stress and long-term effects on child

neurodevelopment: how and why? Journal of Child

Psychology and Psychiatry, 2007. 48(3-4): p. 245-261.

4. Van den Bergh, B.R., et al., Antenatal maternal anxiety and stress and the neurobehavioural development of the fetus and child: links and possible mechanisms. A review. Neuroscience \& Biobehavioral Reviews, 2005. 29(2): p. 237258.

5. Wadhwa, P.D., et al. Developmental origins of health and disease: brief history of the approach and current focus on epigenetic mechanisms. in Seminars in reproductive medicine. 2009. (C) Thieme Medical Publishers.

6. Copper, R.L., et al., The preterm prediction study: Maternal stress is associated with spontaneous preterm birth at less than thirtyfive weeks' gestation. American journal of obstetrics and gynecology, 1996. 175(5): p. 1286-1292.

7. Dole, N., et al., Maternal stress and preterm birth. American journal of epidemiology, 2003. 157(1): p. 14-24.

8. Lobel, M., C. Dunkel-Schetter, and S.C. Scrimshaw, Prenatal maternal stress and prematurity: a prospective study of socioeconomically disadvantaged women. Health psychology, 1992. 11(1): p. 32.

9. Wadhwa, P.D., et al., The association between prenatal stress and infant birth weight and gestational age at birth: a prospective investigation. American journal of obstetrics and gynecology, 1993. 169(4): p. 858-865.

10. Huizink, A.C., et al., Chernobyl exposure as stressor during pregnancy and behaviour in adolescent offspring. Acta Psychiatrica Scandinavica, 2007. 116(6): p. 438-446.

11. O'connor, T.G., et al., Maternal antenatal anxiety and behavioural/emotional problems in children: a test of a programming hypothesis. Journal of child Psychology and Psychiatry, 2003. 44(7): p. 10251036.

12. Barker, E.D. and B. Maughan, Differentiating early-onset persistent versus childhoodlimited conduct problem youth. American Journal of Psychiatry, 2009. 166(8): p. 900-908.

13. Van den Bergh, B.R. and A. Marcoen, High antenatal maternal anxiety is related to ADHD symptoms, externalizing problems, and anxiety in 8-and 9year-olds. Child development, 2004. 75(4): p. 1085-1097.

14. Laplante, D.P., et al., Project Ice Storm: Prenatal maternal stress affects cognitive and linguistic functioning in 51/2-year-old children. Journal of the American Academy of Child \& Adolescent Psychiatry, 2008. 47(9): p. 10631072.

15. Bergman, K., et al., Maternal stress during pregnancy predicts cognitive ability and fearfulness 
in infancy. Journal of the American Academy of Child \& Adolescent Psychiatry, 2007. 46(11): p. 1454-1463.

16. Entringer, S., et al., Prenatal exposure to maternal psychosocial stress and HPA axis regulation in young adults. Hormones and behavior, 2009. 55(2): p. 292-298.

17. Khashan, A.S., et al., Higher risk of offspring schizophrenia following antenatal maternal exposure to severe adverse life events. Archives of general psychiatry, 2008. 65(2): p. 146152.

18. Van Os, J. and J.-P. Selten, Prenatal exposure to maternal stress and subsequent schizophrenia: the May 1940 invasion of the Netherlands. The british journal of psychiatry, 1998. 172(4): p. 324-326.

19. Gutteling, B.M., C. de Weerth, and J.K. Buitelaar, Prenatal stress and children's cortisol reaction to the first day of school. Psychoneuroendocrinology, 2005. 30(6): p. 541-549.

20. Van den Bergh, B.R., et al., Antenatal maternal anxiety is related to HPA-axis dysregulation and self-reported depressive symptoms in adolescence: a prospective study on the fetal origins of depressed mood. Neuropsychopharmacology, 2008. 33(3): p. 536.

21. Yehuda, R., et al., Transgenerational effects of posttraumatic stress disorder in babies of mothers exposed to the World Trade Center attacks during pregnancy. The Journal of Clinical Endocrinology \& Metabolism, 2005. 90(7): p. 4115-4118.

22. Huizink, A.C., et al., Stress during pregnancy is associated with developmental outcome in infancy. Journal of Child Psychology and Psychiatry, 2003. 44(6): p. 810-818.

23. DiPietro, J.A., et al., Maternal psychological distress during pregnancy in relation to child development at age two. Child development, 2006. 77(3): p. 573-587.

24. Kim, E., et al., Effect of maternal job strain during pregnancy on infant neurodevelopment by gender at 6 and 12 months: Mothers and Children's Environmental Health (MOCEH) study. Annals of occupational and environmental medicine, 2015. 27(1): p. 8.

25. St-Hilaire, A., et al., $A$ prospective study of effects of prenatal maternal stress on later eating-disorder manifestations in affected offspring: Preliminary indications based on the project ice storm cohort. International Journal of Eating Disorders, 2015. 48(5): p. 512-516.

26. Rai, D., et al., Prenatal and early life exposure to stressful life events and risk of autism spectrum disorders: populationbased studies in Sweden and England. PloS one, 2012. 7(6): p. e38893.

27. Zhu, P., et al., Sex-specific and time-dependent effects of prenatal stress on the early 
Rechtuijt en Noordermeer Prenatale Stress en Cognitieve, Psychiatrische en Motorische Ontwikkelingsstoornissen van het Kind: systematische review

behavioral symptoms of ADHD: a longitudinal study in China. European child \& adolescent psychiatry, 2015. 24(9): p. 11391147.

28. Betts, K.S., et al., Exposure to stressful life events during pregnancy predicts psychotic experiences via behaviour problems in childhood. Journal of psychiatric research, 2014. 59: p. 132-139.

29. Walder, D.J., et al., Prenatal maternal stress predicts autism traits in $6^{1 / 2}$ year-old children: Project Ice Storm. Psychiatry research, 2014. 219(2): p. 353360.

30. Li, J., et al., Attentiondeficit/hyperactivity disorder in the offspring following prenatal maternal bereavement: a nationwide follow-up study in Denmark. European child \& adolescent psychiatry, 2010. 19(10): p. 747-753.
31. Cao, X., et al., Prenatal maternal stress affects motor function in 51/2-year-old children: Project Ice Storm. Developmental psychobiology, 2014. 56(1): p. 117-125.

32. Laplante, D.P., et al., Stress during pregnancy affects general intellectual and language functioning in human toddlers. Pediatric research, 2004. 56(3): p. 400.

33. Keeser, D., et al., Changes of resting-state EEG and functional connectivity in the sensor and source space of patients with major depression. Klinische Neurophysiologie, 2013. 44(01): p. P142. 